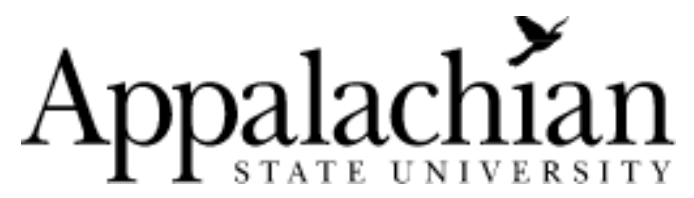

Department of Economics Working Paper

Number 13-02 | February 2013

The (Un)Reliability of Real-Time Output

Gap Estimates

with Revised Data

Onur Ince

Appalachian State University

David H. Papell

University of Houston

Department of Economics

Appalachian State University

Boone, NC 28608

Phone: (828) 262-6123

Fax: (828) 262-6105

www.business.appstate.edu/economics 


\title{
The (Un)Reliability of Real-Time Output Gap Estimates with Revised Data
}

\author{
Onur Ince* \\ David H. Papell ${ }^{* *}$ \\ December 19, 2012
}

\begin{abstract}
This paper investigates the differences between real-time and ex-post output gap estimates using a newly-constructed international real-time data set over the period from 1973:Q1 to 2012:Q3. We extend the findings in Orphanides and van Norden (2002) for the United States that the use of ex-post information in calculating potential output, not the data revisions themselves, is the major cause of the difference between real-time and ex-post output gap estimates to nine additional OECD countries. The results are robust to the use of linear, quadratic, HodrickPrescott, Baxter-King, and Christiano-Fitzgerald detrending methods. By using quasi real-time methods, reliable real-time output gap estimates can be constructed with revised data.
\end{abstract}

Keywords: Output gap, real-time data, data revision, business cycles

JEL Classification: E32, E52, E58.

We thank Simon van Norden, Dean Croushore, Lutz Killian, James Morley, Philipp Maier, Tanya Molodtsova, Munechika Katayama, Anastasia Zervou and participants at Texas Camp Econometrics 2009, the 2009 Annual Missouri Economics Conference, the 2009 Southern Economic Association Conference, and two anonymous referees for helpful comments and discussions.

\footnotetext{
*Department of Economics, Appalachian State University, Boone, NC 28608-2037. Tel: +1 (828) 262-4033. Email: inceo@appstate.edu

** Department of Economics, University of Houston, Houston, TX 77204-5882. Tel: +1 (713) 743-3807. Email: dpapell@uh.edu
} 


\section{Introduction}

An important measure of economic activity is the output gap, the percentage deviation of real output from its long-run trend. The output gap is central to the Phillips Curve where, if actual output exceeds its potential level, inflation tends to rise and, if it is below potential, inflation tends to fall. It is also central to the Taylor rule for monetary policy, where a positive output gap calls for an increase in the interest rate.

Policymakers and researchers face uncertainties while estimating output gaps. Some of these uncertainties are common to both, as the choice of the data, the model, and the detrending technique could result in different output gap estimates. Other types of uncertainties are idiosyncratic. Policymakers estimate output gaps using real-time data, tautologically defined as the data available to policymakers at the time they are making decisions. Researchers, however, typically conduct policy evaluation using revised data that incorporates information available at the time the research is conducted. Output gaps estimated based on real-time data do not allow one to distinguish whether recent changes in the gap are caused by changes in the trend or by fluctuations around the trend. This end-of-sample uncertainty can cause serious problems for policy setters who are required to make decisions in real-time. While policymakers would prefer to have revised data, which better reflects the "true" state of the economy, this is obviously impossible. ${ }^{1}$ Researchers conducting policy evaluation, in contrast, would prefer real-time data that better reflects the information available to policymakers.

Starting with Orphanides (2001), much research has been conducted on the impact of using real-time data for monetary policy evaluation, typically in the context of estimated Taylor rules that include inflation and output gaps. Since the differences between real-time and revised inflation are almost always much smaller than the differences between real-time and revised output gaps, accurate estimation of real-time output gaps is central to this work. We will stipulate that, if real-time data is available, it should be used for policy evaluation. The purpose of this paper is to investigate what researchers should do if real-time data is not available.

Two factors explain the differences between ex-post and real-time output gap estimates. First, output gaps estimated in real-time may be different than output gaps estimated with revised data due to subsequent revisions in the output data itself. Second, with the arrival of new data,

\footnotetext{
${ }^{1}$ Policymakers can, of course, attempt to forecast data revisions. These forecasts, however, would constitute realtime data.
} 
the trend may change even in the absence of data revisions. Orphanides and van Norden (1999, 2002) argue that ex-post revisions of the estimated gap are of the same magnitude as the estimated gap itself. Using a selection of detrending techniques to estimate potential output, they find low correlations between real-time and revised estimates of U.S. output gaps. In the absence of real-time data, they propose constructing quasi real-time output gaps to proxy real-time output gap estimates. Quasi real-time estimation is based on ex-post revised data where the trend does not contain future observations, and to mimic the real-time nature, the gap at period $t$ is calculated using only observations through period $t$. They report high correlations between realtime and quasi real-time estimates of the U.S. output gap, leading them to conclude that most of the differences between real-time and revised estimates of the output gap arise from including realized future output series for the calculation of the trend, not from the data revisions themselves.

A number of subsequent studies have focused on output gap estimates with real-time data for a single country. Using Canadian real-time data with vintages from 1972:Q1 to 2003:Q4, Cayen and van Norden (2005) provide evidence that data revisions are likely to be more important for Canada than for the U.S. Kamada (2005) compares GDP and non-GDP (capital utilization and labor related statistics) based real-time output gap estimates for Japan and finds that GDP based output gap measures are subject to severe real-time estimation problems. Using real-time GDP data for Australia from 1971:Q4 to 2001:Q4, Gruen et al. (2002) find that the output gap estimates obtained using real-time data are quite reliable, with the correlation between the real-time and revised output gaps over 0.8 .

There has been an extensive work on European countries that studied output gap measurement problems for real-time estimates. Nelson and Nikolov (2003) document the differences between real-time and revised output gap estimates for the U.K. using a real-time dataset from 1962:Q4 to 2000:Q4. They also find that real-time output gap estimates contain substantial errors and are on average larger in the U.K. than in the U.S. Garratt et al. (2009) report a similar conclusion as Nelson and Nikolov (2003) for the U.K. using the Bank of England's real-time database. Bernhardsen et al. (2005) find that data revisions are less important than uncertainty about the trend at the end of the sample in estimating the output gap using real-time data for Norway from 1993:Q1 to 2003:Q4. Clausen and Meier (2005) construct a real-time dataset for Germany and calculate various measures of the output gap to estimate an 
interest rate reaction function. Döpke (2004) analyses output gap estimates based on real-time German GDP data from 1980:Q1 to 2001:Q4 and generally finds relatively low correlations between both real-time and revised and quasi real-time and revised estimates. Mitchell (2003) finds substantial uncertainty in output gap density estimates using real-time data for the Euro area from 1992:Q3 to 2003:Q1. Recently, Marcellino and Musso (2011) use real-time real GDP data for the euro area with vintages starting from 2001:Q1 to 2010:Q4 and confirm the uncertainty of real-time estimates of the output gap.

These studies use different series, sample periods, and methods to estimate real-time output gaps for a single country or a zone, and therefore do not allow for a comparison across countries. In order to provide such a comparison, we construct a real-time data set for 10 OECD countries based on information published in the International Financial Statistics (IFS) books from 1973:Q1 to 2012:Q3. Because GDP was not reported with sufficient consistency to construct reliable real-time data for these countries, we measure output by the Industrial Production Index. For three of the ten countries, Germany, the U.K., and the U.S., for which real-time GDP data is available from other sources, we compare the results using both output measures.

We confirm the findings in Orphanides and van Norden (2002) for all 10 countries. For each country, the correlations between real-time and revised output gap estimates are low while the correlations between real-time and quasi real-time output gap estimates are high, implying that changes in the trend as the sample increases play a more important role in output gap estimation than the data revisions themselves. The results are robust to various types of detrending. The same pattern of correlations found with Industrial Production Index data is also found for Germany, the U.K., and the U.S. with real GDP data. Our results show that, if realtime data is not available, output gap estimates based on quasi real-time data can be used as a reliable measure of real-time economic activity.

\section{Output Gap Estimation Methods}

The output gap is defined as the deviation of actual output from potential output. As there is no consensus in the literature on how to define potential output, we use the most common techniques in the literature and calculate the output gap as the percentage deviation of actual output from a linear time trend, a quadratic time trend, an Hodrick-Prescott (1997) (HP) trend, a 
Baxter and King (1999) (BK) trend, and a Christiano and Fitzgerald (2003) trend. All of these detrending methods decompose the log of real output, $y_{t}$ measured by the industrial production index, into a trend component, $T_{t}$ and a cycle component, $c_{t}$ :

$$
y_{t}=T_{t}+c_{t}
$$

1. Linear Time Trend. The trend is a deterministic linear function of time. The log of real output $y_{t}$ is regressed on a constant term and a linear time trend, $X=\{1 \mathrm{t}\}$. The output gap is derived from the residuals from this OLS regression.

2. Quadratic Time Trend. A quadratic term is added in the deterministic component, $X=\left\{1 \mathrm{tt}^{2}\right\}$. The residuals from the regression constitute the output gap.

3. Hodrick-Prescott (HP) Filter. One of the most popular detrending techniques is suggested by Hodrick and Prescott (1997). The output gap is calculated by minimizing the loss-function:

$$
L=\operatorname{argmin} \sum_{t=1}^{T} \hat{y}_{t}^{2}+\lambda \sum_{t=2}^{T-1}\left[\left(T_{t+1}-T_{t}\right)-\left(T_{t}-T_{t-1}\right)\right]
$$

where $\hat{y}_{t}=y_{t}-T_{t}$. The smoothness parameter $\lambda$ punishes the variability in the trend component. An increase in the value of $\lambda$ makes the trend component smoother, and the trend component becomes a linear trend as $\lambda$ approaches to infinity. Following convention, we choose $\lambda=1600$ to detrend quarterly series. ${ }^{2}$ To handle the end-of-sample distortions created by the filter, we apply the technique proposed by Watson (2007) by using an AR (8) model to forecast the log of output 12-quarters ahead before applying the filter. ${ }^{3}$ This is particularly important for real-time and quasi-real-time data, where every output gap estimate is calculated at the end of the sample.

4. Baxter-King (BK) Filter. Another popular detrending technique is suggested by Baxter and King (1999). The BK filter is a symmetric filter that admits frequency components between 6 and 32 quarters in a time series, and is also subject to the end-of-sample problem. We apply the same method proposed by Watson (2007) for the HP filter to get an estimate of output gaps at the end of the sample. In order to impose a unit weight constraint at zero frequency, the optimal filter weights, $a_{h}$ are modified as functions of the weights of the ideal band-pass filter, $b_{h}$ where $a_{h}=b_{h}+\theta$ and $\theta=\left(1-\sum_{h=-K}^{K} b_{h}\right) /(2 K+1) . K$ is the moving average lag length.

5. Christiano-Fitzgerald (CF) Filter. The CF Filter is based on Christiano and Fitzgerald (1999, 2003) that uses the linear approximation that is optimal under the assumption that the data are

\footnotetext{
${ }^{2}$ See for instance van Norden (1995) and St-Amant and van Norden (1998) for detailed discussion of the HP Filter.

${ }^{3}$ Mise, Kim, and Newbold (2005) also show that the HP filter is suboptimal at the end points.
} 
generated by a random walk. The $\mathrm{CF}$ filter isolates the component of $y_{t}$ with a period of oscillation between $p_{l}$ and $p_{u}$, where:

$$
\hat{y}_{t}=B_{0} y_{t}+B_{1} y_{t+1}+\cdots+B_{T-1-t} y_{T-1}+\tilde{B}_{T-t} y_{T}+B_{1} y_{t-1}+\cdots+B_{t-2} y_{2}+\tilde{B}_{t-1} y_{1}
$$

for $t=3,4, \ldots ., T-2$ and the filter weights are:

$$
B_{j}=\frac{\sin (j b)+\sin (j a)}{\pi j}, j \geq 1 \text { and } B_{0}=\frac{b-a}{\pi}, a=\frac{2 \pi}{p_{u}}, b=\frac{2 \pi}{p_{l}}
$$

Specifically, $\widetilde{B}_{T-t}$ is the sum of the $B_{j}$ 's over $j=T-t, T-t+1, \ldots$. and $\widetilde{B}_{t-1}$ is the sum of the $B_{j}$ 's over $j=t-1, t, \ldots$. Since the data is quarterly, $p_{l}$ and $p_{u}$ are chosen as 6 and 32 to admit frequency components between 1.5 and 8 years.

\section{Data}

Real-time data has a triangular format, where columns represent vintages of data, or dates when the data series is published, and rows represent calendar dates. Figure 1 illustrates the structure of real-time data using the first 11 vintages of Canadian industrial production index as an example. Each column represents a series of industrial production available to market participants in every quarter, and each row shows how an observation for each particular date has been revised over time. For example, the first column shows that the series that was published in the International Monetary Fund's International Financial Statistics (IFS) issue for 1973:Q1. The industrial production index series in each data vintage that is used to estimate the output gap goes back to 1958:Q1. The revised data is constructed from the 2012:Q3 vintage, which is the last vintage for all the countries in our sample.

\subsection{Real-Time Datasets for the U.S., Germany, and U.K.}

Real-time data sets for the United States, Germany, and United Kingdom are publicly available and real GDP/GNP is used as a proxy for real output in these datasets. The real-time dataset for the U.S. comes from the Federal Reserve Bank of Philadelphia and is described in detail in Croushore and Stark (2001). We use U.S. real GDP vintages from 1973:Q1 to 2012:Q3, and the data in each vintage goes back to 1947:1. For each available vintage, the new value becomes available with a one-quarter lag.

For Germany, the real-time data set is collected by Gerberding, Worms, and Seitz (2005) at the Bundesbank. The vintages are available from 1973:Q1 to 1998:Q4. Data points in each vintage start in 1962:Q1 and are updated with a one-quarter lag. In order to have endpoint as the 
other real-time data sets, we extend the vintages through 2012:Q3 by splicing OECD real-time GDP data for Germany with the Bundesbank data. ${ }^{4}$

Real-time real GDP data for U.K. is available from the Bank of England's real time database. ${ }^{5}$ The main body of the database contains quarterly vintages of data published since the first quarter of 1990, so that the Bank of England real-time data consists of vintages from 1990:Q1 to 2012:Q3. Real GDP is updated every year following the publication of the Office for National Statistics (ONS) Blue Book. The data in each vintage starts in 1970:Q1 and is updated with a one-quarter lag.

\subsection{IFS Real-Time Dataset}

Real-time data sets are not, however, available for most countries. We construct a realtime data set for 10 OECD countries, Australia, Canada, France, Germany, Italy, Japan, Netherlands, Sweden, the United Kingdom, and the United States, using the International Monetary Fund (IMF) International Financial Statistics (IFS) country pages. The IFS is the IMF's principal statistical publication, and has been published monthly since January 1948. The country pages show major economic aggregates.

We use seasonally adjusted industrial production index (IFS line 66) as a proxy for real output. Industrial production indexes are included as indicators of current economic activity and for some countries they are supplemented by indicators relevant to a particular country (such as tourism). Generally, the coverage of industrial production indexes consists of mining and quarrying, manufacturing and electricity, and gas and water. The indexes are computed using the Laspeyres formula.

The three alternative real-time datasets for the U.S., Germany, and the U.K. described in Section 3.1 use real GDP/GNP as a proxy for real output. Unfortunately, the real GDP/GNP data is not consistently available for all the countries in the IFS country tables. For some countries, especially early in the sample period, real GDP/GNP is either reported annually or reported with a long lag. In contrast to GDP, the industrial production index is updated regularly and made available on a monthly basis. Each vintage in our quarterly real-time data set comprises the data available as of the middle month (February, May, August, and November) of a given quarter. For

\footnotetext{
${ }^{4} \mathrm{http}: / /$ stats.oecd.org/Index.aspx ?querytype=view\&queryname $=206$

${ }^{5}$ http://www.bankofengland.co.uk/statistics/gdpdatabase/index.htm
} 
the 10 OECD countries, including the U.S, used in this study the IFS dataset covers the vintages from 1973:Q1 to 2012:Q3 with data series in each vintage starting in 1958:Q1.

In order to illustrate the relationship between industrial production and real GDP, Figure 2 presents real-time year-over-year growth rates of industrial production and real GDP for the U.S. using vintages from 1973:Q1 to 2012:Q3. ${ }^{6}$ Although the industrial production growth rate is more volatile, the two series track each other very closely and have a correlation of 0.89 . Watson (2007) uses industrial production and real GDP to estimate output gaps and finds that the gaps estimated in real-time using both series have similar patterns. We present further evidence of the similarity between real-time output gaps estimated using industrial production and real GDP in section 5.1.

\section{Measuring Output Gap Uncertainty}

The five detrending methods discussed in Section 2 are applied to each real-time dataset in three different ways to decompose either real GDP or the industrial production index into trend and cycle components and to characterize the role that the revisions play in output gap estimation. We follow Orphanides and van Norden (2002) in constructing and comparing realtime, quasi real-time, and revised estimates of the output gap. ${ }^{7}$

To construct real-time output gaps, we first estimate the output gap for the last date in each series, starting with 1958:Q1 - 1972:Q4 and ending with 1958:Q1 - 2012:Q2, using the data available in each quarter from 1973:Q1 to 2012:Q3. We then use these vintages of estimated output gaps to construct a new series of real-time output gaps by pairing vintage dates with the last available observations in each quarter, generally available with a one-quarter lag. In order to construct revised output gap estimates, we use the last vintage, 2012:Q3, in each dataset. The entire series available in the last vintage date is used to estimate the revised trend. Quasi realtime output gaps are constructed in exactly the same way as real-time output gaps, using the data up to period t to estimate the output gap for period $t$, but are estimated using revised data.

Output gaps estimated using the same techniques with real-time and revised data might be different because of (1) the data revisions themselves and (2) the additional observations with revised data affect the trend which measures potential output and, therefore, the deviations from

\footnotetext{
${ }^{6}$ The data is taken from the real time-data set of the Federal Reserve Bank of Philadelphia. The figure presents the latest available year-to-year growth rate of both series in each vintage.

${ }^{7}$ Orphanides and van Norden (2002) refer to revised output gap estimates as "final" estimates in their work.
} 
the trend. ${ }^{8}$ Real-time and quasi real-time output gaps are estimated using data for exactly the same period and differ only because of the revisions in the data. Revised and quasi real-time output gaps differ only because of changes in the trend. The use of real-time, quasi real-time, and revised estimates allows us to compare the importance of the two factors and determine whether reliable estimates of real-time output gaps can be constructed with revised data.

\section{Results}

\subsection{Output Gap Estimates for Germany, U.S., and U.K Using IFS and Alternative Real-Time}

Data Sets

The relationships between real-time, revised, and quasi real-time output gap estimates are first examined visually by plotting them in pairs for the U.S. Figure 3 displays HP filtered output gap for the U.S. estimated using the Philadelphia Fed real-time dataset as in Orphanides and van Norden (2002), extending the sample size to 2012:Q3. ${ }^{9}$ Two observations can be made based on visual examination of three panels, which depict real-time and revised output gaps (Panel A), quasi real-time and revised output gaps (Panel B), and real-time and quasi real-time output gaps (Panel C). First, both real-time and revised estimates and quasi real-time and revised estimates on Panels A and B exhibit substantial differences throughout the sample. Second, the differences between real-time and quasi real-time output gap estimates on Panel $\mathrm{C}$ are much less pronounced. ${ }^{10}$

Table 1 provides summary statistics for five output gap measures in percentage points estimated using real-time, revised, and quasi real-time data for Germany, U.K., and the U.S, which illustrates these points in a more formal way. Panels A, C, and E report summary statistics calculated using real GDP data from the Bundesbank, the Bank of England and the Philadelphia Federal Reserve Bank, respectively, while Panels B, D, and F rely on industrial production index from IMF International Financial Statistics.

The average German, U.K., and U.S. real-time and quasi real-time output gap estimates are very close and mostly negative for all output gap measures except the output gap estimated

\footnotetext{
${ }^{8}$ Orphanides (2003) mentions the difficulty of estimating real-time output gap in the presence of trend shifts that occur due to the arrival of new data.

${ }^{9}$ Orphanides and van Norden (2002) use 2000:Q1 as revised data, and we use 2012:Q3.

${ }^{10}$ While output gaps estimated using other detrending methods sometimes differ in sign and/or magnitude from the HP filtered gaps, the differences between real-time, revised, and quasi real-time output gap estimates show similar patterns as in Figure 3.
} 
using quadratic trend, while the average revised output gap estimates for the three countries are generally positive and close to zero. ${ }^{11}$ The differences between the average real-time and revised output gap range between 0.5 and 14.5 percentage points for Germany, 0.3 and 8.8 percentage points for U.K., and 0.2 and 10.2 percentage points for the U.S. The differences between the average quasi real-time and revised output gap estimates range between 0.4 and 14.5 percentage points for Germany, 0.2 and 7.6 percentage points for the U.K., and 0.3 and 8.4 percentage points for the U.S.

More evidence on the relative importance of output gap revisions is given in Table 2. Column 2 presents the mean of total revisions (derived by subtracting real-time output gap estimates from revised estimates) for each detrending method. While the average revision is relatively small in magnitude for the HP, BK, and CF filters, it is larger for the linear and quadratic trends for each country. The finding in Orphanides and van Norden (2002) that the revisions in the U.S. output gap are of the same order of magnitude as the estimated output gaps can be extended to Germany and U.K. as well. The last 3 columns of Table 2 report relative importance of the revisions in different ways. NS and NSR are two proxies for the noise-tosignal ratio. While NS is the ratio of the standard deviation of the total revision to the standard deviation of the revised output gap estimate, NSR is the ratio of the root mean square of the total revision to standard deviation of the revised output gap estimate. In general, the revisions have relatively larger variance to the revised estimate of the output gaps for linear and quadratic trends compared to the HP, BK, and CF filters. The last column reports the OPSIGN, the frequency of opposite signs with real-time and revised output gap estimates. The frequency of opposite signs for each filter obtained with IFS real-time data is very similar to the alternative German, U.K., and U.S. real-time datasets.

Tables 3-5 report the correlations between quasi real-time and real-time, real-time and revised, and quasi real-time and revised output gap estimates for the U.S., Germany, and the U.K. Panels A and B of each table report correlations obtained using alternative real-time dataset (Bundesbank, Bank of England, and Philadelphia Federal Reserve Bank real-time datasets) and the IFS dataset, respectively.

\footnotetext{
${ }^{11}$ One would expect the average revised output gap to be close to zero. Although we calculate the trend starting from the initial data point in each vintage, the statistics are reported for the output gaps estimated starting from 1990:Q1 for the Bank of England's real-time data and 1973:Q1 for the other data sets.
} 
Table 3 reports correlations for the U.S. output gap estimates based on the two datasets that span the same time period, from 1973:Q1 to 2012:Q3. The correlations between real-time and quasi real-time output gap estimates range from 0.920 for the BK filtered output gap to 0.953 for the quadratic trend using the Philadelphia Fed real-time data. The correlations between realtime and revised estimates, however, are much lower, ranging from 0.729 for the HP filter to 0.873 for the linear trend while the correlations between revised and quasi real-time estimates are in between, ranging from 0.717 for the HP filter to 0.952 for the linear trend.

The correlations obtained using the IFS dataset are close to those obtained with Philadelphia Fed dataset. The correlations between real-time and quasi real-time output gap estimates range from 0.921 for the HP filter to 0.954 for the quadratic trend, while the correlations between real-time and revised estimates are lower, ranging from 0.509 for the quadratic trend to 0.849 for the linear trend. Thus, the output gaps calculated using both real GDP (Philadelphia Fed) and industrial production index (IFS) data demonstrate high correlations between real-time and quasi-real output gap estimates and relatively low correlations between real-time and revised output gap estimates.

Table 4 reports correlations for output gap estimates using the Bundesbank and IFS realtime datasets for Germany. Using Bundesbank data, the correlations between real-time and quasi real-time output gap estimates are high, ranging from 0.909 for the HP filter to 0.945 for the CF filter. The correlations between real-time and revised estimates are again much lower, ranging from 0.002 for quadratic trend to 0.870 for linear trend while the correlations between revised and quasi real-time estimates are in between, ranging from 0.115 for the quadratic trend to 0.887 for the linear trend. The results obtained using IFS data display a similar pattern. The correlations between real-time and quasi real-time estimates range from 0.974 for the linear trend to 0.987 for the quadratic trend and the BK Filter, the correlations between real-time and revised estimates range from 0.208 for the quadratic trend to 0.796 for the $\mathrm{CF}$ filter, and the correlations between revised and quasi real-time estimates range from 0.236 for the quadratic trend to 0.805 for the CF filter. ${ }^{12}$ Correlations between real-time and revised output gap estimates with IFS data for Germany are higher with the HP and BK filters and lower with quadratic trend compared to Döpke (2004).

\footnotetext{
${ }^{12}$ These results are in accord with Clausen and Meier (2005), who find low correlations between real-time and revised output gaps for Germany using the same sample period 1973Q1 to 1998:Q4 with Bundesbank data set.
} 
Table 5 reports the correlations between U.K. output gap estimates obtained using the Bank of England and IFS real-time datasets. Using Bank of England data, correlations between real-time and quasi real-time output gap estimates range from 0.943 for the BK filter to 0.970 for the quadratic trend. The correlations between real-time and revised estimates are lower and range from 0.605 to 0.938 , while the correlations between revised and quasi real-time estimates range from 0.583 for the HP filter to 0.863 for the linear trend. With IFS data, the correlations between real-time and quasi real-time output gap estimates range from 0.948 for the HP filter to 0.972 for the linear trend. The correlations between real-time and revised estimates are lower, ranging from 0.422 for the quadratic trend to 0.928 for the linear trend, while the correlations between revised and quasi real-time estimates range from 0.398 for the quadratic trend to 0.960 for the linear trend. Correlations between real-time and revised output gap estimates with IFS data for the U.K. with the HP and BK filters are very similar to Garratt et al. (2009) and Nelson and Nikolov (2003).

\subsection{Output Gap Estimates for 7 OECD Countries Using IFS Real-Time Data Set}

Central bank real-time data that spans the period from 1973:Q1 are not available for other OECD countries and were collected from IMF International Financial Statistics country pages. Table 6 reports summary statistics for five output gap measures in percentage points estimated using real-time, revised, and quasi real-time data for Australia, Canada, France, Italy, Japan, Netherlands, and Sweden. While the means of real-time and quasi real-time output gap estimates are negative with the linear trend, the HP filter, the BK filter, and the CF filter they are positive with the quadratic trend. The differences between real-time and revised output gap estimates for these countries (ranging from 0.5 percentage points for Australia to 42.8 percentage points for Japan) are relatively much larger than the differences between real-time and quasi real-time output gap estimates (varying from 0 for France, Sweden to 1.2 percentage points for Italy). Table 7 presents the output gap revisions in more detail. First, total revisions are greater on average for the linear trend, where the mean varies from 10 percentage points for Australia to 42.8 percentage points for Japan. Second, output gap estimates revised downwards with the quadratic trend for all the countries. Third, noise-to-signal ratios are similar for the HP, BK, and CF filters. Finally, it is worth noting that OPSIGN mostly exceeds 50 percent for the linear and quadratic trends and stays lower for the HP, BK and CF filters. 
Table 8 reports the correlations between real-time and quasi real-time, real-time and revised, and quasi real-time and revised output gap estimates obtained using IFS data for Australia, Canada, France, Italy, Japan, Netherlands, and Sweden. The correlations between realtime and quasi-real time estimates for Canada, France, Japan, Netherlands, and Sweden are higher than either the correlations between real-time and revised estimates or the correlations between quasi real-time and revised estimates. This result does not depend on which detrending technique is used. Results in Panel B for Canada confirm Cayen and van Norden (2005) that correlations between real-time and revised output gap estimates are low and might even be negative depending on the filter chosen. Correlations between real-time and quasi-real time estimates vary from 0.811 to 0.923 for Canada, from 0.914 to 0.977 for France, from 0.975 to 0.994 for Japan, from 0.879 to 0.984 for Netherlands, and from 0.869 to 0.947 for Sweden. Quasi-real time output gap estimates constitute a good proxy measure for real-time output gap estimates.

Although the correlations between real-time and quasi-real time estimates for Australia and Italy are always higher than the correlations between real-time and revised estimates, they are not always higher than the correlations between quasi real-time and revised estimates. For Australia (Panel A), while the highest correlations with linear and quadratic trend are observed between real-time and quasi-real estimates, the highest correlations with HP Filter, BK Filter, and CF Filter are between quasi real-time and revised estimates. Correlations of output gap estimates with the HP Filter for Australia are in accord with Gruen et al. (2002). The results for Italy (Panel D) show that the correlations between real-time and quasi real-time output gap estimates are highest except for the linear trend.

\section{Conclusions}

Although the output gap plays an important role in the design of monetary policy for central banks, constructing reliable measures of output gaps presents a challenge. Since real-time and revised output gaps can differ significantly, real-time output gaps can provide an inaccurate representation of what will later be understood to have been the "true" output gap, and the use of output gaps estimated with ex-post data can lead to an inaccurate assessment of the information available to policymakers. 
For the United States, Orphanides and van Norden (2002) find that changes in the trend from extending the sample play a much more crucial role in the difference between real-time and revised output gap estimates than the data revisions themselves. We extend their work by constructing a real-time data set for 10 OECD countries using industrial production index data published in the International Financial Statistics books from 1973:Q1 to 2012:Q3. We also use real-time GDP data for three countries - Germany, the United Kingdom, and the United States for which the data is available from alternate sources. Using a variety of output measures and detrending techniques, we find that the correlations between real-time and revised output gap estimates are low for each country and the correlations between real-time and quasi real-time output gap estimates are high for each country, confirming their findings for all 10 countries.

In order to conduct policy evaluation, such as estimation of Taylor rules, researchers would prefer to have real-time output gap data that reflects the information available to policymakers. Unfortunately, real-time data needed to construct real-time output gaps is only available for very few countries. We show that, if real-time data is not available, one can substitute quasi real-time gaps constructed by using revised data, but only estimating the trends through the date of the gap. In this manner, researchers can construct reliable real-time output gap estimates with revised data. 


\section{REFERENCES}

Baxter, M., King, R., 1999. "Measuring Business Cycles: Approximate Band-Pass Filters for Economic Time Series," The Review of Economics and Statistics, 81, 575-593.

Bernhardsen, T., Eitrheim, Ø., Jore, A.S., Roisland, Ø., 2005. "Real Time Data for Norway: Challenges for Monetary Policy," The North American Journal of Economics and Finance 16, 333-349.

Cayen, J.-P., van Norden, S., 2005. "The Reliability of Canadian Output Gap Estimates," The North American Journal of Economics and Finance 16, 373-393.

Christiano, L.J., Fitzgerald, T.J., 1999. “The Band Pass Filter,” NBER Working Papers 7257, National Bureau of Economic Research, Inc.

Christiano, L.J., Fitzgerald, T.J., 2003. "The Band Pass Filter," International Economic Review $44,435-465$.

Clausen, J.R., Meier, C.-P., 2005. "Did the Bundesbank Follow a Taylor Rule? An Analysis Based on Real-Time Data," Swiss Journal of Economics and Statistics 127, 213-246.

Croushore, D., Stark, T., 2001. “A Real-Time Data Set for Macroeconomists," Journal of Econometrics 105, 111-130.

Döpke, J., 2004. "Real-Time Data and Business Cycle Analysis in Germany," Journal of Business Cycle Measurement and Analysis 1, 337-361.

Garratt, A., Lee, K., Mise, E., Shields K., 2009. "Real Time Representation of the Output Gap in the UK in the Presence of Model Uncertainty," International Journal of Forecasting 25, 81 102.

Gerberding, C., Seitz, F., Worms, A., 2005. "How the Bundesbank Really Conducted Monetary Policy: An Analysis Based on Real-Time Data," The North American Journal of Economics and Finance 16, 277-292.

Gruen, D., Robinson, T., Stone, A., 2002. "Output Gaps in Real Time: Are They Reliable Enough to Use for Monetary Policy?" Reserve Bank of Australia Research Discussion Paper 2002-06.

Hodrick, R.J., Prescott, E.C., 1997. "Postwar U.S. Business Cycles: An Empirical Investigation," Journal of Money, Credit, and Banking 29, 1-16.

Kamada, K., 2005. "Real-time Estimation of the Output Gap in Japan and Its Usefulness for Inflation Forecasting and Policymaking," North American Journal of Economics and Finance 16, 309-332. 
Marcellino, M., Musso, A., 2011. "The Reliability of Real-Time Estimates of the Euro Area Output Gap," Economic Modelling 28, 1842-1856.

Mise, E., Kim, T.-H., Newbold, P., 2005. "On Suboptimality of the Hodrick-Prescott Filter at Time Series Endpoints,” Journal of Macroeconomics 27, 53-67.

Mitchell, J., 2003. "Should We Be Surprised by the Unreliability of Real-Time Output Gap Estimates? Density Estimates for the Euro Area," Manuscript, National Institute of Economic and Social Research.

Nelson, E., Nikolov, K., 2003. "UK Inflation in the 1970s and 1980s: The Role of Output Gap Mismeasurement," Journal of Economics and Business 55, 353-370.

Orphanides, A., 2001. "Monetary Policy Rules Based on Real-Time Data," American Economic Review 91, 964-985.

Orphanides, A., 2003. "The Quest for Prosperity without Inflation," Journal of Monetary Economics 50, 633-663.

Orphanides, A., van Norden, S., 1999. "The Reliability of Output Gap Estimates in Real Time," Board of Governors of the Federal Reserve System, Finance and Economics Discussion Series, 1999-38.

Orphanides, A., van Norden, S., 2002. "The Unreliability of Output Gap Estimates in Real Time," Review of Economics and Statistics 84, 569-583.

St-Amant, P., van Norden, S., 1998. "Measurement of the Output Gap: A Discussion of Recent Research at the Bank of Canada," Bank of Canada Technical Report 1998-79.

van Norden, S., 1995." Why Is It So Hard to Measure the Current Output Gap?” Manuscript, Bank of Canada.

Watson, M., 2007. "How Accurate Are Real-Time Estimates of Output Trends and Gaps?" Federal Reserve Bank of Richmond Economic Quarterly 93, 143-161. 


\begin{tabular}{|c|c|c|c|c|c|c|c|c|c|c|c|}
\hline Vintage & 1973Q1 & 1973Q2 & 1973Q3 & 1973Q4 & 1974Q1 & 1974Q2 & 1974Q3 & 1974Q4 & 1975Q1 & 1975Q2 & 1975Q3 \\
\hline \multicolumn{12}{|l|}{ Date } \\
\hline 1958Q1 & 73.87 & 73.87 & 73.87 & 73.87 & 73.87 & 73.87 & 73.87 & 73.87 & 73.87 & 73.87 & 73.87 \\
\hline 1958Q2 & 75.14 & 75.14 & 75.14 & 75.14 & 75.14 & 75.14 & 75.14 & 75.14 & 75.14 & 75.14 & 75.14 \\
\hline 1958Q3 & 73.87 & 73.87 & 73.87 & 73.87 & 73.87 & 73.87 & 73.87 & 73.87 & 73.87 & 73.87 & 73.87 \\
\hline 1958Q4 & 75.77 & 75.77 & 75.77 & 75.77 & 75.77 & 75.77 & 75.77 & 75.77 & 75.77 & 75.77 & 75.77 \\
\hline$\ldots$ & $\ldots$ & $\ldots$ & $\ldots$ & $\ldots$ & $\ldots$ & $\ldots$ & $\ldots$ & $\ldots$ & $\ldots$ & $\ldots$ & \\
\hline 1972Q1 & 164.90 & 164.90 & 164.90 & 164.90 & 166.40 & 166.40 & 166.27 & 166.27 & 167.79 & 167.79 & 167.79 \\
\hline 1972Q2 & 170.10 & 168.40 & 168.40 & 168.40 & 169.40 & 169.40 & 169.31 & 169.31 & 170.37 & 170.37 & 170.37 \\
\hline 1972Q3 & 168.30 & 168.40 & 168.40 & 168.40 & 168.70 & 168.70 & 168.70 & 168.70 & 170.22 & 170.22 & 170.22 \\
\hline 1972Q4 & . & 175.30 & 175.60 & 175.60 & 177.40 & 177.40 & 177.35 & 177.35 & 178.41 & 178.41 & 178.41 \\
\hline 1973Q1 & . & . & 180.70 & 180.70 & 182.50 & 182.50 & 182.51 & 182.51 & 183.87 & 183.87 & 183.87 \\
\hline 1973Q2 & . & . & . & 185.20 & 184.80 & 184.80 & 185.24 & 185.24 & 186.00 & 186.00 & 186.00 \\
\hline 1973Q3 & . & . & . & . & 183.00 & 183.60 & 183.57 & 183.57 & 184.94 & 184.94 & 184.94 \\
\hline 1973Q4 & . & . & . & . & . & 187.80 & 188.27 & 188.27 & 189.64 & 189.64 & 189.64 \\
\hline 1974Q1 & . & . & . & . & . & . & 193.73 & 193.73 & 194.34 & 193.89 & 193.89 \\
\hline 1974Q2 & . & . & . & . & . & . & . & 192.37 & 192.82 & 192.07 & 192.07 \\
\hline 1974Q3 & . & . & . & . & . & . & . & . & 190.25 & 189.94 & 189.94 \\
\hline 1974Q4 & . & . & . & . & . & . & . & 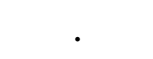 & . & 187.21 & 187.51 \\
\hline 1975Q1 & . & . & . & . & . & . & . & 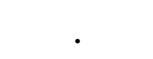 & . & . & 182.51 \\
\hline
\end{tabular}

Note: The real-time data for industrial production consists of vintages from 1973:Q1 to 2012:Q3. Each column represents a series of industrial production available to market participants in every quarter, and each row shows how an observation for each particular date has been revised over time.

\section{Figure 1. The Structure of Real-Time Data}




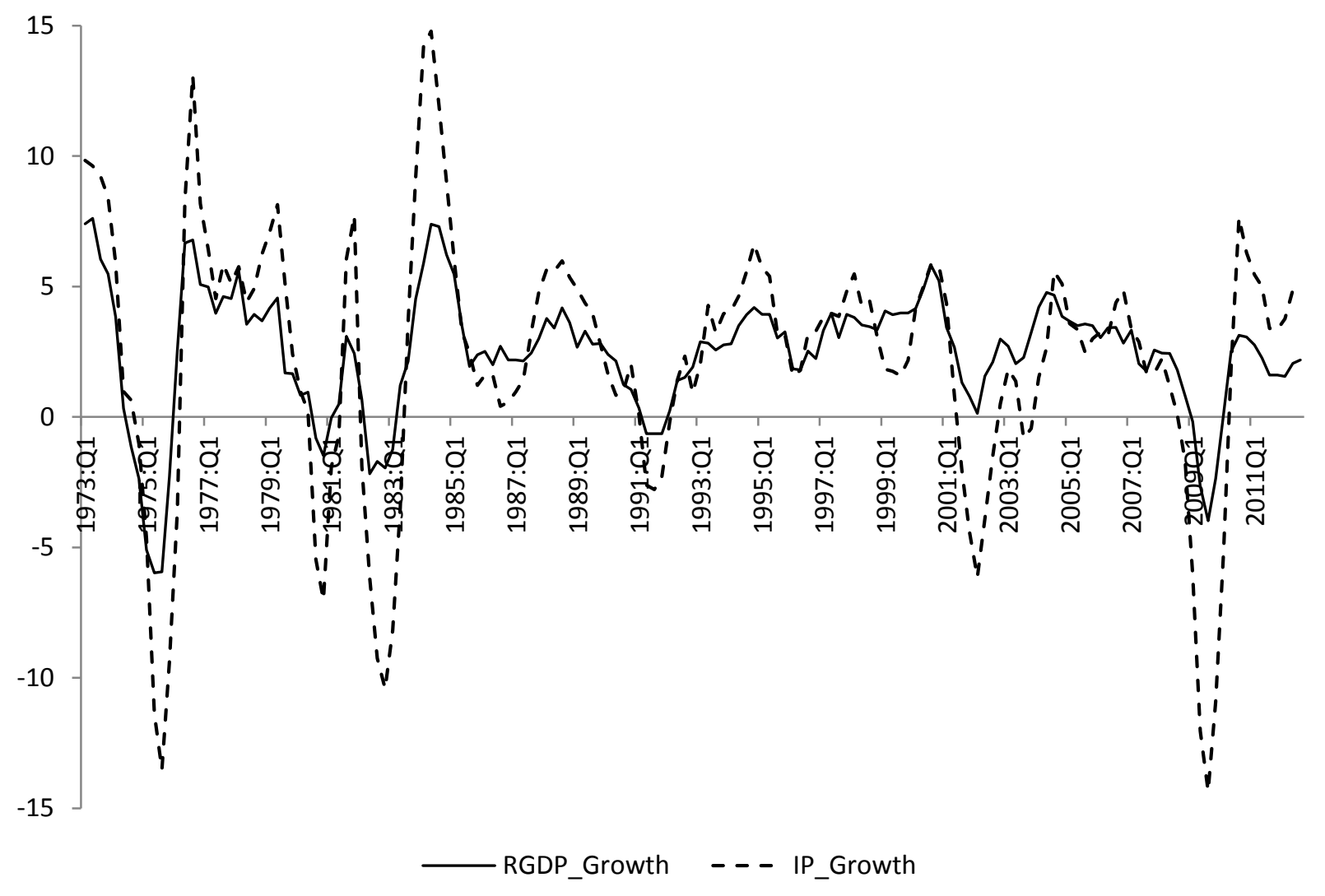

Figure 2. Year-to-Year Real GDP and Industrial Production Growth for the U.S. using Philadelphia Fed Real-Time Dataset 


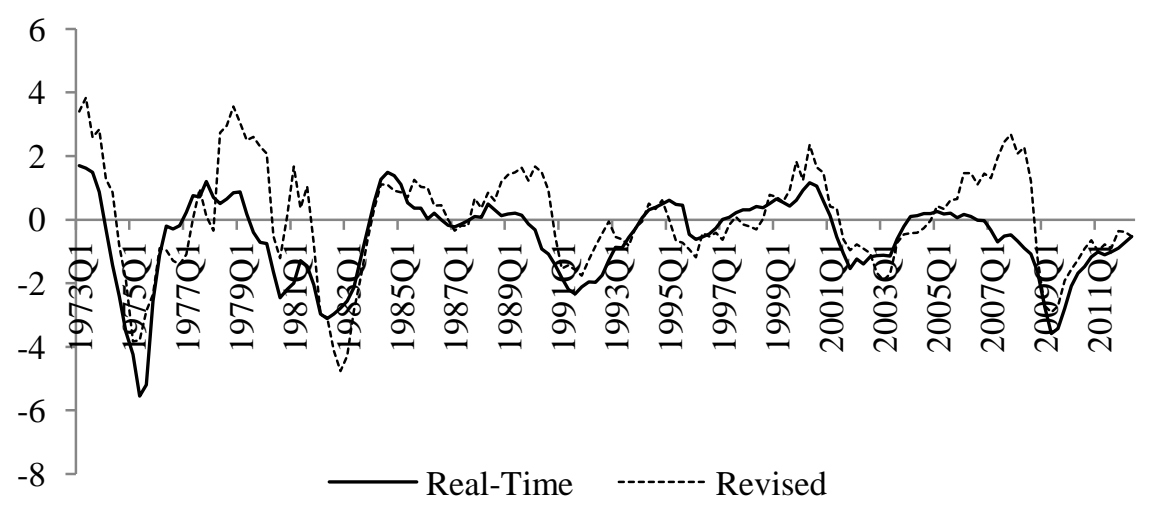

Panel A. Real-Time and Revised Output Gap

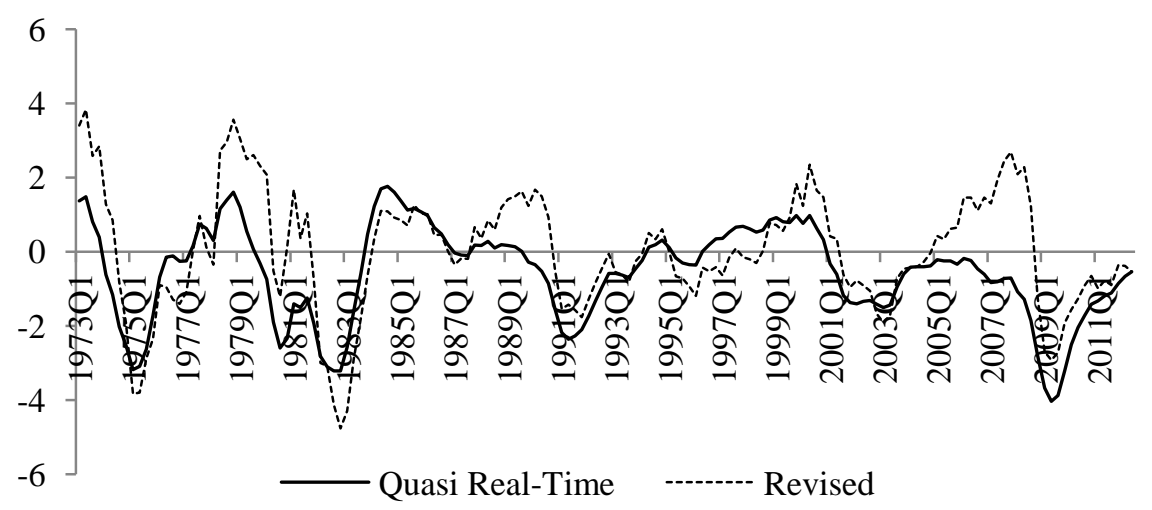

Panel B. Quasi Real-Time and Revised Output Gap

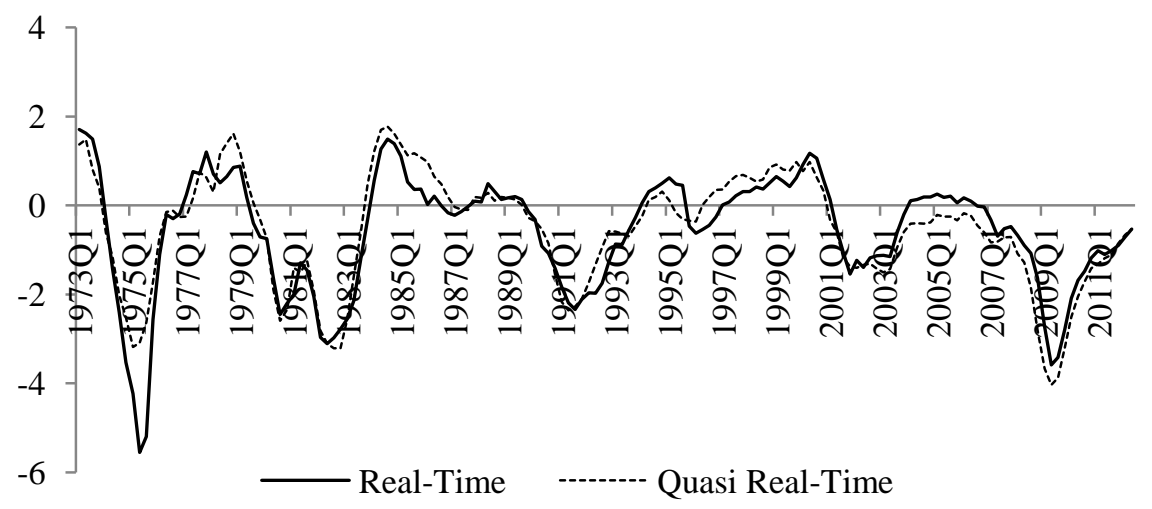

Panel C. Real-Time and Quasi Real-Time Output Gap

Figure 3. Output Gap Estimates for the U.S. using Philadelphia Fed Real-Time Dataset 
Table 1. Output Gap Summary Statistics Using Alternative and IFS Real-Time Datasets

\begin{tabular}{|c|c|c|c|c|c|c|c|c|c|c|c|c|}
\hline & \multicolumn{4}{|c|}{ Real-Time } & \multicolumn{4}{|c|}{ Revised } & \multicolumn{4}{|c|}{ Quasi Real-Time } \\
\hline & Mean & SD & Min & $\operatorname{Max}$ & Mean & SD & Min & Max & Mean & SD & Min & Max \\
\hline & \multicolumn{12}{|c|}{ A. Germany: Bundesbank Data } \\
\hline Linear Trend & -6.8 & 3.2 & -15.8 & -0.3 & 1.5 & 5.4 & -12.4 & 10.5 & -6.5 & 3.4 & -15.1 & 2.3 \\
\hline Quadratic Trend & 1.2 & 3.0 & -7.7 & 9.2 & 0.0 & 3.1 & -7.7 & 8.8 & 1.6 & 3.2 & -6.7 & 11.5 \\
\hline HP Filter & -0.8 & 1.1 & -4.8 & 1.4 & 0.0 & 1.6 & -4.2 & 4.1 & -0.7 & 1.1 & -3.6 & 2.2 \\
\hline BK Filter & -0.7 & 1.0 & -5.6 & 1.1 & 0.0 & 1.5 & -4.2 & 3.8 & -0.7 & 1.0 & -3.9 & 1.9 \\
\hline \multirow[t]{2}{*}{ CF Filter } & -0.5 & 1.0 & -3.7 & 1.0 & 0.0 & 1.6 & -4.1 & 4.0 & -0.4 & 1.0 & -3.5 & 1.4 \\
\hline & \multicolumn{12}{|c|}{ B. Germany: IFS Data } \\
\hline Linear Trend & -12.2 & 5.2 & -25.6 & 2.4 & 2.3 & 9.1 & -22.7 & 20.8 & -12.2 & 5.3 & -25.0 & 1.1 \\
\hline Quadratic Trend & 5.0 & 6.6 & -12.4 & 19.3 & -0.1 & 7.2 & -12.4 & 16.7 & 5.1 & 6.7 & -11.9 & 20.5 \\
\hline HP Filter & -1.1 & 2.3 & -9.6 & 3.8 & 0.0 & 3.8 & -14.6 & 10.4 & -1.1 & 2.3 & -9.5 & 3.8 \\
\hline BK Filter & -1.0 & 2.3 & -12.3 & 4.3 & 0.0 & 3.7 & -14.0 & 11.4 & -1.0 & 2.4 & -12.0 & 4.3 \\
\hline \multirow[t]{2}{*}{ CF Filter } & -0.8 & 2.2 & -10.6 & 4.0 & 0.0 & 3.7 & -14.3 & 11.4 & -0.7 & 2.2 & -10.4 & 4.0 \\
\hline & \multicolumn{12}{|c|}{ C. U.K.: Bank of England Data } \\
\hline Linear Trend & 0.0 & 3.5 & -9.9 & 4.6 & 0.4 & 4.1 & -9.9 & 6.7 & 1.6 & 4.1 & -9.9 & 6.1 \\
\hline Quadratic Trend & -2.7 & 3.4 & -11.5 & 1.7 & 0.4 & 4.2 & -11.5 & 6.0 & -2.6 & 3.7 & -11.5 & 1.9 \\
\hline HP Filter & -0.5 & 1.0 & -3.0 & 0.8 & -0.1 & 1.3 & -2.8 & 3.6 & -0.3 & 1.1 & -3.4 & 0.9 \\
\hline BK Filter & -0.4 & 0.9 & -3.2 & 0.8 & 0.0 & 1.3 & -2.8 & 4.2 & -0.2 & 1.0 & -3.4 & 1.0 \\
\hline \multirow[t]{2}{*}{ CF Filter } & -0.3 & 1.0 & -2.9 & 1.8 & 0.0 & 1.2 & -2.9 & 3.2 & -0.2 & 1.0 & -3.1 & 1.9 \\
\hline & \multicolumn{12}{|c|}{ D. U.K.: IFS Data } \\
\hline Linear Trend & -7.7 & 6.6 & -25.0 & 3.2 & 1.1 & 7.7 & -21.9 & 12.5 & -6.5 & 6.3 & -24.9 & 2.6 \\
\hline Quadratic Trend & 0.2 & 5.7 & -15.0 & 10.6 & -0.5 & 5.5 & -12.2 & 9.7 & 1.1 & 5.6 & -14.7 & 10.3 \\
\hline HP Filter & -1.1 & 1.9 & -6.0 & 3.4 & 0.0 & 2.6 & -6.4 & 7.7 & -0.8 & 1.9 & -5.8 & 2.9 \\
\hline BK Filter & -1.0 & 1.7 & -6.3 & 3.4 & 0.1 & 2.4 & -6.6 & 5.8 & -0.7 & 1.7 & -6.2 & 2.6 \\
\hline \multirow[t]{2}{*}{ CF Filter } & -0.7 & 1.6 & -6.1 & 2.7 & 0.1 & 2.4 & -6.1 & 6.3 & -0.4 & 1.5 & -5.2 & 2.6 \\
\hline & \multicolumn{12}{|c|}{ E. U.S.: Philadelphia Fed Data } \\
\hline Linear Trend & -5.9 & 3.6 & -15.1 & 2.6 & 0.6 & 5.2 & -15.1 & 9.7 & -5.1 & 3.8 & -15.2 & 2.3 \\
\hline Quadratic Trend & -0.4 & 3.3 & -10.4 & 6.2 & -0.2 & 3.3 & -8.2 & 5.9 & -0.5 & 3.3 & -7.6 & 6.2 \\
\hline HP Filter & -0.6 & 1.3 & -5.6 & 1.7 & 0.0 & 1.6 & -4.8 & 3.8 & -0.6 & 1.3 & -4.0 & 1.8 \\
\hline BK Filter & -0.6 & 1.2 & -5.8 & 1.8 & 0.0 & 1.5 & -4.4 & 3.5 & -0.5 & 1.2 & -4.0 & 1.7 \\
\hline \multirow[t]{2}{*}{ CF Filter } & -0.3 & 1.0 & -4.0 & 2.0 & 0.0 & 1.5 & -4.0 & 4.3 & -0.3 & 1.0 & -3.2 & 2.0 \\
\hline & \multicolumn{12}{|c|}{ F. U.S.: IFS Data } \\
\hline Linear Trend & -8.0 & 6.2 & -25.8 & 3.8 & 1.2 & 7.9 & -21.2 & 13.9 & -7.2 & 6.5 & -25.2 & 6.0 \\
\hline Quadratic Trend & 2.2 & 6.0 & -16.1 & 12.3 & -0.4 & 6.4 & -16.3 & 12.7 & 2.8 & 6.2 & -15.4 & 14.1 \\
\hline HP Filter & -10.2 & 2.7 & -9.4 & 4.3 & 0.0 & 3.5 & -11.5 & 7.0 & -0.9 & 2.9 & -10.5 & 4.4 \\
\hline BK Filter & -1.1 & 2.6 & -9.9 & 4.2 & 0.1 & 3.3 & -9.5 & 7.7 & -0.8 & 2.8 & -10.3 & 4.5 \\
\hline CF Filter & -0.6 & 2.0 & -6.7 & 3.5 & 0.1 & 3.3 & -9.3 & 9.1 & -0.5 & 2.0 & -6.7 & 3.9 \\
\hline
\end{tabular}

Note: The statistics reported for each variable are Mean, the mean, SD, the standard deviation, Min, and Max, the minimum and maximum values of output gap estimates in percentage points. 
Table 2. Summary Revision Statistics Using Alternative and IFS Real-Time Datasets

\begin{tabular}{|c|c|c|c|c|c|c|c|}
\hline & Mean & SD & Min & Max & NS & NSR & OPSIGN \\
\hline & \multicolumn{7}{|c|}{ A. Germany: Bundesbank Data } \\
\hline Linear Trend & 8.3 & 3.1 & 0.0 & 13.5 & 0.6 & 1.6 & 0.7 \\
\hline Quadratic Trend & -1.3 & 4.4 & -10.8 & 10.0 & 1.4 & 1.4 & 0.4 \\
\hline HP Filter & 0.8 & 1.3 & -2.7 & 4.5 & 0.8 & 1.0 & 0.4 \\
\hline BK Filter & 0.8 & 1.1 & -2.0 & 3.8 & 0.8 & 0.9 & 0.4 \\
\hline \multirow[t]{2}{*}{ CF Filter } & 0.5 & 1.1 & -2.2 & 3.6 & 0.7 & 0.8 & 0.3 \\
\hline & \multicolumn{7}{|c|}{ B. Germany: IFS Data } \\
\hline Linear Trend & 14.5 & 7.9 & 0.0 & 27.8 & 0.9 & 1.8 & 0.5 \\
\hline Quadratic Trend & -5.2 & 8.7 & -15.6 & 18.3 & 1.2 & 1.4 & 0.6 \\
\hline HP Filter & 1.1 & 2.5 & -9.1 & 8.0 & 0.6 & 0.7 & 0.2 \\
\hline BK Filter & 1.1 & 2.3 & -8.3 & 9.7 & 0.6 & 0.7 & 0.3 \\
\hline \multirow[t]{2}{*}{ CF Filter } & 0.8 & 2.4 & -3.8 & 10.0 & 0.6 & 0.7 & 0.3 \\
\hline & \multicolumn{7}{|c|}{ C. U.K.: Bank of England Data } \\
\hline Linear Trend & 0.4 & 1.5 & -2.2 & 2.9 & 0.4 & 0.4 & 0.1 \\
\hline Quadratic Trend & 3.1 & 2.1 & 0.0 & 6.7 & 0.5 & 0.9 & 0.4 \\
\hline HP Filter & 0.4 & 1.1 & -1.0 & 3.5 & 0.8 & 0.8 & 0.3 \\
\hline BK Filter & 0.4 & 1.0 & -1.3 & 3.9 & 0.8 & 0.9 & 0.4 \\
\hline \multirow[t]{2}{*}{ CF Filter } & 0.3 & 0.9 & -1.5 & 3.1 & 0.8 & 0.8 & 0.3 \\
\hline & \multicolumn{7}{|c|}{ D. U.K.: IFS Data } \\
\hline Linear Trend & 8.8 & 2.9 & 0.0 & 18.8 & 0.4 & 1.2 & 0.6 \\
\hline Quadratic Trend & -0.7 & 6.0 & -13.7 & 10.4 & 1.1 & 1.1 & 0.4 \\
\hline HP Filter & 1.2 & 1.8 & -2.4 & 8.2 & 0.7 & 0.8 & 0.3 \\
\hline BK Filter & 1.1 & 1.6 & -2.3 & 5.5 & 0.7 & 0.8 & 0.4 \\
\hline \multirow[t]{2}{*}{ CF Filter } & 0.8 & 1.6 & -2.1 & 4.9 & 0.7 & 0.7 & 0.3 \\
\hline & \multicolumn{7}{|c|}{ E. U.S.: Philadelphia Fed Data } \\
\hline Linear Trend & 6.5 & 2.7 & -0.5 & 12.0 & 0.5 & 1.4 & 0.6 \\
\hline Quadratic Trend & 0.2 & 2.2 & -4.9 & 7.1 & 0.7 & 0.7 & 0.2 \\
\hline HP Filter & 0.6 & 1.1 & -2.0 & 3.7 & 0.7 & 0.8 & 0.3 \\
\hline BK Filter & 0.6 & 1.0 & -2.0 & 3.2 & 0.7 & 0.8 & 0.2 \\
\hline \multirow[t]{2}{*}{ CF Filter } & 0.3 & 1.0 & -1.8 & 2.8 & 0.7 & 0.7 & 0.3 \\
\hline & \multicolumn{7}{|c|}{ F. U.S.: IFS Data } \\
\hline Linear Trend & 9.2 & 4.2 & 0.0 & 23.9 & 0.5 & 1.3 & 0.6 \\
\hline Quadratic Trend & -2.6 & 6.2 & -13.7 & 13.0 & 1.0 & 1.0 & 0.4 \\
\hline HP Filter & 1.2 & 2.5 & -4.7 & 8.3 & 0.7 & 0.8 & 0.3 \\
\hline BK Filter & 1.2 & 2.2 & -4.0 & 8.1 & 0.7 & 0.8 & 0.3 \\
\hline CF Filter & 0.7 & 2.4 & -4.6 & 8.3 & 0.7 & 0.7 & 0.3 \\
\hline
\end{tabular}

Note: The statistics reported for each variable are Mean, the mean, SD, the standard deviation, Min, and Max, the minimum and maximum values of total revisions. NS and NSR are proxies for the noise-to-signal ratio. OPSIGN is the frequency of opposite signs with real-time and revised estimates. 
Table 3. Correlations between Real-Time, Revised, and Quasi Real-Time Output Gaps for the U.S. using Philadelphia Fed and IFS Real-Time Datasets

\begin{tabular}{c|c|c|c}
\hline \multirow{2}{*}{$\begin{array}{c}\text { (Real-Time, } \\
\text { Revised) }\end{array}$} & $\begin{array}{c}\text { (Quasi Real-Time, } \\
\text { Revised })\end{array}$ & $\begin{array}{c}\text { (Real-Time, Quasi } \\
\text { Real-Time) }\end{array}$ \\
\hline \multicolumn{3}{c}{ A. Philadelphia Fed Real-Time Data } \\
\hline Quadratic Trend & 0.873 & 0.952 & 0.923 \\
HP Filter & 0.729 & 0.783 & 0.953 \\
BK Filter & 0.745 & 0.717 & 0.922 \\
CF Filter & 0.738 & 0.737 & 0.920 \\
\hline \multicolumn{2}{c|}{ B. IFS Real-Time Data } & 0.940 \\
\hline Linear Trend & 0.849 & 0.895 & 0.950 \\
Quadratic Trend & 0.509 & 0.566 & 0.954 \\
HP Filter & 0.717 & 0.784 & 0.921 \\
BK Filter & 0.743 & 0.794 & 0.926 \\
CF Filter & 0.723 & 0.793 & 0.922 \\
\hline
\end{tabular}

Note: The table reports the correlations of linear, quadratic, HP-filtered, BK-filtered and CF-filtered output gaps, estimated with real-time and revised data, quasi real-time and revised data, and real-time and quasi real-time data. 
Table 4. Correlations between Real-Time, Revised, and Quasi Real-Time Output Gaps for Germany using Bundesbank and IFS Real-Time Datasets

\begin{tabular}{c|c|c|c}
\hline & $\begin{array}{c}\text { (Real-Time, } \\
\text { Revised) }\end{array}$ & $\begin{array}{c}\text { (Quasi Real-Time, } \\
\text { Revised })\end{array}$ & $\begin{array}{c}\text { (Real-Time, Quasi } \\
\text { Real-Time) }\end{array}$ \\
\hline \multicolumn{3}{c}{ A. Bundesbank Real-Time Data } \\
\hline Qunear Trend & 0.870 & 0.887 & 0.928 \\
Quadratic Trend & 0.002 & 0.115 & 0.939 \\
HP Filter & 0.578 & 0.725 & 0.909 \\
BK Filter & 0.654 & 0.728 & 0.915 \\
CF Filter & 0.705 & 0.791 & 0.945 \\
\hline \multicolumn{2}{|c}{ B. IFS Real-Time Data } & 0.974 \\
\hline Linear Trend & 0.500 & 0.472 & 0.987 \\
Quadratic Trend & 0.208 & 0.236 & 0.986 \\
HP Filter & 0.789 & 0.796 & 0.987 \\
BK Filter & 0.779 & 0.794 & 0.986 \\
CF Filter & 0.796 & 0.805 & \\
\hline
\end{tabular}

Note: The table reports the correlations of linear, quadratic, HP-filtered, BK-filtered and CF-filtered output gaps, estimated with real-time and revised data, quasi real-time and revised data, and real-time and quasi real-time data. 
Table 5. Correlations between Real-Time, Revised, and Quasi Real-Time Output Gaps for the U.K. using Bank of England and IFS Real-Time Datasets

\begin{tabular}{c|c|c|c}
\hline & $\begin{array}{c}\text { (Real-Time, } \\
\text { Revised) }\end{array}$ & $\begin{array}{c}\text { (Quasi Real-Time, } \\
\text { Revised })\end{array}$ & $\begin{array}{c}\text { (Real-Time, Quasi } \\
\text { Real-Time) }\end{array}$ \\
\hline \multicolumn{4}{c}{ A. Bank of England Real-Time Data } \\
\hline Linear Trend & 0.938 & 0.863 & 0.950 \\
Quadratic Trend & 0.872 & 0.818 & 0.970 \\
HP Filter & 0.631 & 0.583 & 0.949 \\
BK Filter & 0.605 & 0.588 & 0.943 \\
CF Filter & 0.670 & 0.682 & 0.952 \\
\hline \multicolumn{4}{|c}{ B. IFS Real-Time Data } \\
\hline Linear Trend & 0.928 & 0.960 & 0.972 \\
Quadratic Trend & 0.422 & 0.398 & 0.971 \\
HP Filter & 0.722 & 0.752 & 0.948 \\
BK Filter & 0.746 & 0.764 & 0.951 \\
CF Filter & 0.766 & 0.781 & 0.960 \\
\hline
\end{tabular}

Note: The Bank of England real-time data consists of vintages from 1990:Q1 to 2012:Q3, and IFS real-time data consists of vintages from 1973:Q1 to 2012:Q3. The table reports the correlations of linear, quadratic, HP-filtered, BK-filtered and CF-filtered output gaps, estimated with real-time and revised data, quasi real-time and revised data, and real-time and quasi real-time data. 
Table 6. Output Gap Summary Statistics Using IFS Real-Time Dataset

\begin{tabular}{|c|c|c|c|c|c|c|c|c|c|c|c|c|}
\hline & \multicolumn{4}{|c|}{ Real-Time } & \multicolumn{4}{|c|}{ Revised } & \multicolumn{4}{|c|}{ Quasi Real-Time } \\
\hline & Mean & SD & Min & Max & Mean & SD & Min & Max & Mean & SD & Min & $\operatorname{Max}$ \\
\hline \multicolumn{13}{|c|}{ A. Australia } \\
\hline Linear Trend & -8.5 & 5.0 & -24.0 & 8.1 & 1.5 & 6.8 & -15.6 & 20.5 & -8.9 & 4.6 & -25.2 & 2.6 \\
\hline Quadratic Trend & 4.6 & 5.6 & -10.0 & 24.0 & -0.2 & 5.7 & -15.4 & 17.0 & 4.3 & 5.3 & -10.6 & 14.3 \\
\hline HP Filter & -0.8 & 2.5 & -9.2 & 8.9 & 0.1 & 2.9 & -9.7 & 7.0 & -1.0 & 2.4 & -9.4 & 4.0 \\
\hline BK Filter & -0.8 & 2.1 & -8.0 & 7.0 & 0.1 & 2.6 & -7.9 & 7.6 & -1.0 & 2.1 & -8.6 & 3.0 \\
\hline CF Filter & -0.4 & 1.8 & -5.2 & 6.5 & 0.1 & 2.7 & -8.0 & 7.1 & -0.5 & 1.7 & -6.6 & 2.8 \\
\hline \multicolumn{13}{|c|}{ B. Canada } \\
\hline Linear Trend & -11.8 & 5.9 & -28.7 & 0.8 & 2.2 & 9.4 & -11.8 & 23.1 & -11.5 & 6.6 & -32.1 & 0.8 \\
\hline Quadratic Trend & 5.7 & 7.3 & -13.2 & 17.3 & 0.1 & 8.8 & -18.4 & 18.9 & 6.0 & 7.9 & -15.3 & 20.1 \\
\hline HP Filter & -1.0 & 2.0 & -6.3 & 2.9 & 0.1 & 3.4 & -13.3 & 6.2 & -0.8 & 2.1 & -6.1 & 4.1 \\
\hline BK Filter & -0.9 & 1.9 & -7.1 & 2.6 & 0.1 & 3.2 & -10.9 & 5.8 & -0.8 & 2.0 & -7.0 & 4.9 \\
\hline CF Filter & -0.7 & 2.0 & -6.5 & 3.9 & 0.1 & 3.3 & -9.8 & 6.1 & -0.6 & 2.2 & -6.8 & 3.8 \\
\hline \multicolumn{13}{|c|}{ C. France } \\
\hline Linear Trend & -15.7 & 6.8 & -35.0 & 6.5 & 3.7 & 12.4 & -29.8 & 25.8 & -15.7 & 6.5 & -35.5 & 3.6 \\
\hline Quadratic Trend & 2.7 & 6.9 & -15.9 & 14.4 & 0.0 & 6.6 & -11.5 & 17.7 & 2.7 & 6.8 & -16.9 & 14.8 \\
\hline HP Filter & -1.6 & 2.2 & -9.6 & 3.2 & 0.0 & 2.8 & -10.1 & 6.5 & -1.6 & 2.1 & -11.8 & 1.8 \\
\hline BK Filter & -1.4 & 1.8 & -7.9 & 1.7 & 0.1 & 2.7 & -9.3 & 7.1 & -1.4 & 1.7 & -8.5 & 1.4 \\
\hline CF Filter & -0.8 & 1.7 & -7.4 & 1.7 & 0.0 & 2.5 & -9.0 & 5.9 & -0.8 & 1.7 & -7.5 & 1.5 \\
\hline \multicolumn{13}{|c|}{ D. Italy } \\
\hline Linear Trend & -20.8 & 8.4 & -47.4 & $\begin{array}{l}-2.8 \\
\end{array}$ & 4.3 & 15.8 & -42.3 & 29.7 & -19.6 & 8.5 & $\begin{array}{l}-47.8 \\
\end{array}$ & -1.8 \\
\hline Quadratic Trend & 3.9 & 6.0 & -14.1 & 13.1 & -0.4 & 6.6 & -12.8 & 15.2 & 5.1 & 5.9 & -14.5 & 14.7 \\
\hline HP Filter & -2.3 & 2.5 & -9.6 & 2.7 & 0.0 & 3.9 & -12.8 & 10.5 & -1.8 & 2.5 & -9.9 & 3.8 \\
\hline BK Filter & -2.1 & 2.1 & -11.8 & 2.0 & 0.2 & 3.7 & -11.9 & 10.7 & -1.7 & 2.3 & -12.2 & 3.3 \\
\hline CF Filter & -1.7 & 2.8 & -15.7 & 2.3 & 0.1 & 4.6 & -18.1 & 11.7 & -1.9 & 2.8 & -15.1 & 2.3 \\
\hline \multicolumn{13}{|c|}{ E. Japan } \\
\hline Linear Trend & -35.1 & 12.3 & -77.5 & -4.7 & 7.7 & 26.9 & -62.9 & 43.9 & -36.0 & 11.8 & -75.1 & -5.9 \\
\hline Quadratic Trend & 8.7 & 8.8 & -22.6 & 25.1 & -0.8 & 9.1 & -16.3 & 27.1 & 8.1 & 9.0 & -22.8 & 24.4 \\
\hline HP Filter & -1.6 & 3.3 & -17.8 & 15.4 & -0.1 & 5.1 & -24.0 & 11.8 & -1.7 & 3.1 & -15.9 & 10.6 \\
\hline BK Filter & -1.6 & 3.8 & -18.3 & 21.3 & 0.1 & 4.9 & -18.6 & 12.9 & -1.7 & 3.5 & -16.9 & 15.7 \\
\hline CF Filter & -1.7 & 2.8 & -15.7 & 2.3 & 0.1 & 4.6 & -18.1 & 11.7 & -1.9 & 2.8 & -15.1 & 2.3 \\
\hline \multicolumn{13}{|c|}{ F. Netherlands } \\
\hline Linear Trend & -18.7 & 5.9 & -32.0 & 3.6 & 3.9 & 12.7 & -24.4 & 29.6 & -17.9 & 5.5 & -30.6 & 0.9 \\
\hline Quadratic Trend & 4.5 & 7.8 & -15.1 & 16.7 & 0.0 & 8.0 & -12.4 & 21.1 & 5.2 & 8.0 & -13.1 & 16.8 \\
\hline HP Filter & -1.4 & 1.6 & -7.1 & 2.9 & 0.0 & 2.5 & -8.4 & 6.7 & -1.2 & 1.7 & -7.6 & 2.7 \\
\hline BK Filter & -1.1 & 1.2 & -4.7 & 1.7 & 0.1 & 2.2 & -7.1 & 6.4 & -1.0 & 1.2 & -5.8 & 1.5 \\
\hline CF Filter & -1.1 & 1.3 & -5.8 & 1.8 & 0.0 & 2.3 & -6.9 & 6.4 & -1.0 & 1.4 & -4.9 & 1.8 \\
\hline \multicolumn{13}{|c|}{ G. Sweden } \\
\hline Linear Trend & -10.6 & 9.3 & -29.4 & 6.5 & 1.3 & 10.3 & -25.4 & 25.2 & -10.9 & 9.3 & -30.2 & 7.4 \\
\hline Quadratic Trend & 7.8 & 9.6 & -15.5 & 27.4 & -0.5 & 10.2 & -27.3 & 21.1 & 7.5 & 9.4 & -16.4 & 27.7 \\
\hline HP Filter & -0.8 & 2.6 & -9.5 & 6.7 & 0.1 & 4.5 & -14.8 & 10.0 & -0.9 & 2.5 & -9.3 & 4.5 \\
\hline BK Filter & -0.8 & 2.3 & -11.1 & 3.6 & 0.1 & 4.2 & -15.3 & 10.5 & -0.8 & 2.3 & -11.2 & 3.6 \\
\hline CF Filter & -0.7 & 2.7 & -11.0 & 5.6 & 0.0 & 3.9 & -14.9 & 9.9 & -0.7 & 2.6 & -11.1 & 5.1 \\
\hline
\end{tabular}

Note: The statistics reported for each variable are Mean, the mean, SD, the standard deviation, Min, and Max, the minimum and maximum values of output gap estimates in percentage points. 
Table 7. Summary Revision Statistics Using IFS Real-Time Dataset

\begin{tabular}{|c|c|c|c|c|c|c|c|}
\hline & Mean & SD & Min & Max & NS & NSR & OPSIGN \\
\hline & \multicolumn{7}{|c|}{ A. Australia } \\
\hline Linear Trend & 10.0 & 6.9 & -10.4 & 23.8 & 1.0 & 1.8 & 0.6 \\
\hline Quadratic Trend & -4.8 & 8.7 & -33.1 & 17.5 & 1.5 & 1.7 & 0.5 \\
\hline HP Filter & 0.9 & 2.8 & -14.1 & 7.5 & 0.9 & 1.0 & 0.3 \\
\hline BK Filter & 0.9 & 2.3 & -11.7 & 5.0 & 0.9 & 0.9 & 0.4 \\
\hline \multirow[t]{2}{*}{ CF Filter } & 0.5 & 2.2 & -10.2 & 5.5 & 0.8 & 0.8 & 0.3 \\
\hline & \multicolumn{7}{|c|}{ B. Canada } \\
\hline Linear Trend & 14.1 & 9.2 & -1.1 & 28.0 & 1.0 & 1.8 & 0.5 \\
\hline Quadratic Trend & -5.6 & 12.1 & -21.3 & 19.1 & 1.4 & 1.5 & 0.6 \\
\hline HP Filter & 1.0 & 2.7 & -7.7 & 7.9 & 0.8 & 0.8 & 0.3 \\
\hline BK Filter & 1.1 & 2.5 & -5.7 & 7.9 & 0.8 & 0.9 & 0.3 \\
\hline \multirow[t]{2}{*}{ CF Filter } & 0.7 & 2.4 & -6.0 & 7.2 & 0.7 & 0.8 & 0.2 \\
\hline & \multicolumn{7}{|c|}{ C. France } \\
\hline Linear Trend & 19.4 & 8.6 & 0.0 & 35.0 & 0.7 & 1.7 & 0.6 \\
\hline Quadratic Trend & -2.6 & 9.5 & -18.0 & 20.2 & 1.4 & 1.5 & 0.5 \\
\hline HP Filter & 1.6 & 2.0 & -3.0 & 7.1 & 0.7 & 0.9 & 0.4 \\
\hline BK Filter & 1.6 & 1.8 & -2.4 & 7.1 & 0.7 & 0.9 & 0.4 \\
\hline \multirow[t]{2}{*}{ CF Filter } & 0.9 & 1.7 & -2.8 & 6.1 & 0.7 & 0.8 & 0.4 \\
\hline & \multicolumn{7}{|c|}{ D. Italy } \\
\hline Linear Trend & 25.2 & 9.7 & 0.0 & 40.7 & 0.6 & 1.7 & 0.7 \\
\hline Quadratic Trend & -4.3 & 6.7 & -15.8 & 11.5 & 1.0 & 1.2 & 0.4 \\
\hline HP Filter & 2.3 & 2.8 & -4.6 & 12.1 & 0.7 & 0.9 & 0.3 \\
\hline BK Filter & 2.3 & 2.6 & -3.2 & 12.6 & 0.7 & 0.9 & 0.4 \\
\hline \multirow[t]{2}{*}{ CF Filter } & 1.8 & 3.1 & -4.6 & 13.2 & 0.7 & 0.8 & 0.3 \\
\hline & \multicolumn{7}{|c|}{ E. Japan } \\
\hline Linear Trend & 42.8 & 16.6 & 0.0 & 57.4 & 0.6 & 1.7 & 0.6 \\
\hline Quadratic Trend & -9.6 & 10.9 & -21.4 & 26.2 & 1.2 & 1.6 & 0.6 \\
\hline HP Filter & 1.5 & 4.8 & -39.5 & 11.5 & 0.9 & 1.0 & 0.3 \\
\hline BK Filter & 1.7 & 4.7 & -37.0 & 12.5 & 1.0 & 1.0 & 0.4 \\
\hline \multirow[t]{2}{*}{ CF Filter } & 1.8 & 3.1 & -4.6 & 13.2 & 0.7 & 0.8 & 0.3 \\
\hline & \multicolumn{7}{|c|}{ F. Netherlands } \\
\hline Linear Trend & 22.6 & 10.7 & 0.0 & 38.3 & 0.8 & 2.0 & 0.6 \\
\hline Quadratic Trend & -4.4 & 12.9 & -20.3 & 25.4 & 1.6 & 1.7 & 0.7 \\
\hline HP Filter & 1.4 & 1.9 & -4.9 & 6.5 & 0.8 & 0.9 & 0.4 \\
\hline BK Filter & 1.2 & 1.7 & -3.1 & 6.7 & 0.8 & 0.9 & 0.5 \\
\hline \multirow[t]{2}{*}{ CF Filter } & 1.1 & 1.5 & -2.2 & 5.7 & 0.7 & 0.8 & 0.4 \\
\hline & \multicolumn{7}{|c|}{ G. Sweden } \\
\hline Linear Trend & 11.9 & 10.2 & -5.4 & 33.6 & 1.0 & 1.5 & 0.5 \\
\hline Quadratic Trend & -8.3 & 13.0 & -36.2 & 21.5 & 1.3 & 1.5 & 0.4 \\
\hline HP Filter & 0.8 & 3.8 & -7.4 & 11.7 & 0.9 & 0.9 & 0.4 \\
\hline BK Filter & 0.9 & 3.3 & -7.2 & 10.6 & 0.8 & 0.8 & 0.3 \\
\hline CF Filter & 0.7 & 3.5 & -7.2 & 11.0 & 0.9 & 0.9 & 0.3 \\
\hline
\end{tabular}

Note: The statistics reported for each variable are Mean, the mean, SD, the standard deviation, Min, and Max, the minimum and maximum values of total revisions. NS and NSR are proxies for the noise-to-signal ratio. OPSIGN is the frequency of opposite signs with real-time and revised estimates. 
Table 8. Correlations between Real-Time, Revised, and Quasi Real-Time Output Gaps using IFS Real-Time Dataset

\begin{tabular}{|c|c|c|c|}
\hline & (Real-Time, Revised) & $\begin{array}{l}\text { (Quasi Real-Time, } \\
\text { Revised) }\end{array}$ & $\begin{array}{c}\text { (Real-Time, Quasi Real- } \\
\text { Time) }\end{array}$ \\
\hline \multicolumn{4}{|c|}{ A. Australia } \\
\hline Linear Trend & 0.353 & 0.485 & 0.654 \\
\hline Quadratic Trend & -0.184 & 0.010 & 0.783 \\
\hline HP Filter & 0.488 & 0.818 & 0.638 \\
\hline BK Filter & 0.549 & 0.802 & 0.701 \\
\hline CF Filter & 0.603 & 0.824 & 0.741 \\
\hline \multicolumn{4}{|c|}{ B. Canada } \\
\hline Linear Trend & 0.349 & 0.339 & 0.866 \\
\hline Quadratic Trend & -0.113 & 0.000 & 0.923 \\
\hline HP Filter & 0.615 & 0.711 & 0.832 \\
\hline BK Filter & 0.617 & 0.714 & 0.811 \\
\hline CF Filter & 0.685 & 0.783 & 0.875 \\
\hline \multicolumn{4}{|c|}{ C. France } \\
\hline Linear Trend & 0.748 & 0.808 & 0.972 \\
\hline Quadratic Trend & 0.012 & -0.029 & 0.977 \\
\hline HP Filter & 0.714 & 0.736 & 0.914 \\
\hline BK Filter & 0.754 & 0.778 & 0.917 \\
\hline CF Filter & 0.732 & 0.751 & 0.931 \\
\hline \multicolumn{4}{|c|}{ D. Italy } \\
\hline Linear Trend & 0.852 & 0.920 & 0.917 \\
\hline Quadratic Trend & 0.426 & 0.433 & 0.838 \\
\hline HP Filter & 0.697 & 0.801 & 0.805 \\
\hline BK Filter & 0.722 & 0.820 & 0.859 \\
\hline CF Filter & 0.741 & 0.736 & 0.984 \\
\hline \multicolumn{4}{|c|}{ E. Japan } \\
\hline Linear Trend & 0.907 & 0.901 & 0.994 \\
\hline Quadratic Trend & 0.263 & 0.257 & 0.993 \\
\hline HP Filter & 0.424 & 0.503 & 0.976 \\
\hline BK Filter & 0.441 & 0.514 & 0.975 \\
\hline CF Filter & 0.741 & 0.736 & 0.984 \\
\hline \multicolumn{4}{|c|}{ F. $\quad$ Netherlands } \\
\hline Linear Trend & 0.545 & 0.532 & 0.957 \\
\hline Quadratic Trend & -0.324 & -0.309 & 0.984 \\
\hline HP Filter & 0.657 & 0.743 & 0.879 \\
\hline BK Filter & 0.624 & 0.702 & 0.884 \\
\hline CF Filter & 0.765 & 0.823 & 0.898 \\
\hline \multicolumn{4}{|c|}{ G. Sweden } \\
\hline Linear Trend & 0.466 & 0.524 & 0.919 \\
\hline Quadratic Trend & 0.137 & 0.186 & 0.947 \\
\hline HP Filter & 0.510 & 0.710 & 0.869 \\
\hline BK Filter & 0.630 & 0.730 & 0.876 \\
\hline CF Filter & 0.491 & 0.718 & 0.884 \\
\hline
\end{tabular}

The table reports the correlations of linear, quadratic, HP-filtered, BK-filtered and CF-filtered output gaps, estimated with real-time and revised data, quasi real-time and revised data, and real-time and quasi real-time data. 